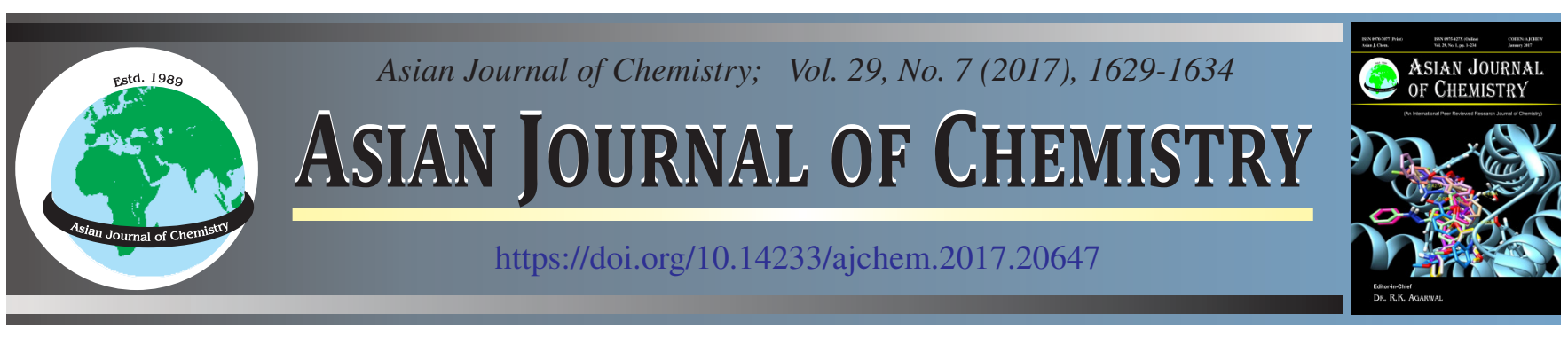

\title{
Simultaneous Estimation of Salbutamol, Oxtriphylline and Bromhexine Hydrochloride in Tablet Dosage Form by RP-HPLC
}

\author{
K.S. Chakravarthi ${ }^{1}$ and N. Devanna ${ }^{2}$
}

${ }^{1}$ Department of Technical Education, Government Polytechnic, Hyderabad-500 001, India

${ }^{2}$ Department of Chemistry, Jawaharlal Nehru Technological University Anantapur, Ananthapuramu-515 001, India

*Corresponding author: E-mail: chakravarthihplc@gmail.com

Received: 13 March 2017;

Accepted: 25 March 2017;

Published online: 13 May 2017;

AJC-18408

\begin{abstract}
A simple, rapid, accurate, specific and stability indicating reverse phase HPLC method has been developed and validated for the simultaneous estimation of salbutamol, oxtriphylline and bromhexine hydrochloride in bulk drug and pharmaceutical tablet dosage form. The chromatographic separation was performed on the kromasil $\mathrm{C}_{18}$ column $(250 \mathrm{~mm} \times 4.6 \mathrm{~mm}, 5 \mu \mathrm{m}$ particle size $)$, using a mobile phase of orthophosphoric acid buffer:acetonitrile $(65: 35 \mathrm{v} / \mathrm{v})$, at a flow rate of $1.0 \mathrm{~mL} / \mathrm{min}$ at an ambient temperature of $25^{\circ} \mathrm{C}$ with the detection wavelength at $260 \mathrm{~nm}$. The retention times of salbutamol, oxtriphylline and bromhexine hydrochloride was found to be $2.03,2.90$ and $4.92 \mathrm{~min}$, respectively. The proposed method has been validated for linearity, range, precision, accuracy and robustness were within the acceptance limit according to ICH Q2R1 guidelines. Quantification of the components in actual tablet formulations was calculated against the responses of freshly prepared external standard solutions. In the linearity test correlation coefficient was found to be 0.999 for all the molecules, percentage relative standard deviation (RSD) results from precision studies were $0.7,0.2$ and 0.3 ; mean percentage recoveries in accuracy studies were found to be $99.33,99.44$ and $99.36 \%$ for salbutamol, oxtriphylline and bromhexine hydrochloride, respectively. Very low concentrations of LOD and LOQ indicate the method was highly sensitive enough. The designed validated method can be used effectively in the laboratory for regular determination of salbutamol, oxtriphylline and bromhexine hydrochloride in tablet formulation and bulk form.
\end{abstract}

Keywords: Salbutamol, Oxtriphylline, RP-HPLC, Method development, Method validation.

\section{INTRODUCTION}

Salbutamol is a 1:1 mixture of R-enantiomer and $\mathrm{S}$ enantiomer. R-enantiomer has bronchodilatory and antiinflammatory effects and S-enantiomer is associated with increased airway hyper reactivity and pro-inflammatory effects [1]. The literature survey reveals that, salbutamol is reported in USP [2]. Few HPLC methods are reported for the determination of salbutamol [3], related substances [4-7] and enantiomeric separation [8]. The IUPAC name of salbutamol is 4-[2-(tertbutylamino)-1-hydroxyethyl]-2-(hydroxymethyl)phenol (Fig. 1). Bromhexine $\mathrm{HCl}$ is a mucolytic agent used in the treatment of respiratory disorders associated with viscid or excessive mucus. In addition, bromhexine $\mathrm{HCl}$ has antioxidant properties [9]. According to IUPAC it is 2,4-dibromo-6-[cyclohexyl(methyl)amino]methyl]aniline hydrochloride (Fig. 2) with a molecular weight of 412.6 and m.f. $\mathrm{C}_{14} \mathrm{H}_{20} \mathrm{~N}_{2} \mathrm{Br} \cdot \mathrm{HCl}$. A number of methods have been developed for the estimation of bromhexine individually and also in combined forms along with other drugs which include HPLC [10-15], spectrophotometry [16-20], fluorimetry [21]. Oxtriphylline is a bronchodilator used to treat the symptoms of asthma, bronchitis and emphysema. The IUPAC name of oxtriphylline 3,7-dihydro-1,3-dimethyl-1H-purine-2,6-dione salt of 2hydroxy-N,N,N-trimethylethanaminium (Fig. 3). There were no reported methods for the estimation of oxtri-phylline either alone or in combination with other drugs. Hence as per the literature survey it was felt that simple, rapid, accurate, specific and sensitive reverse phase HPLC method has to be developed and validated for the simultaneous estimation of salbutamol, oxtriphylline and bromhexine hydrochloride in bulk drug and pharmaceutical dosage form.<smiles>CC(C)(C)NCC(O)c1ccc(O)c(CO)c1</smiles>

Fig. 1. Structure of salbutamol 
<smiles>CN(Cc1cc(Br)cc(Br)c1N)C1CCCCC1</smiles>

Fig. 2. Structure of bromhexine $\mathrm{HCl}$<smiles>Cn1c(=O)c2[nH]cnc2n(C)c1=O</smiles>

Fig. 3. Structure of oxtriphylline

\section{EXPERIMENTAL}

Reference standards of salbutamol, oxtriphylline and bromhexine hydrochloride were supplied by Spectrum Pharma Pvt. Ltd Hyderabad. The solvents used are of HPLC grade. Acetonitrile and orthophosphoric acid were procured from Thermo Fischer Scientific India Pvt. Ltd. Milli Q Water was used in the buffer preparation.

Equipment: A Waters e2695 gradient system with Empower2 software and $2489 \mathrm{UV} / v i s i b l e$ detector is the most sensitive and versatile dual wave length absorbance detector was used. It was manufactured by the company Waters, Alliance HPLC systems, Japan. Intelligent LC pump with sampler programmed at $20 \mu \mathrm{L}$ capacity per injection was used

Chromatographic conditions: The column used was kromasil C18 Column $(150 \mathrm{~mm} \times 4.6 \mathrm{~mm}, 5 \mu \mathrm{m}$ particle size $)$ was used for analytical separation. The mobile phase consists of $0.1 \%$ OPA and acetonitrile in the ratio of $(65: 35 \% \mathrm{v} / \mathrm{v})$. The flow was adjusted to $1 \mathrm{~mL} / \mathrm{min}$. The instrument was operated at an ambient temperature. The UV detection was achieved at $260 \mathrm{~nm}$. The isobestic point showing in Fig 4. The injection volume was $10 \mu \mathrm{L}$.

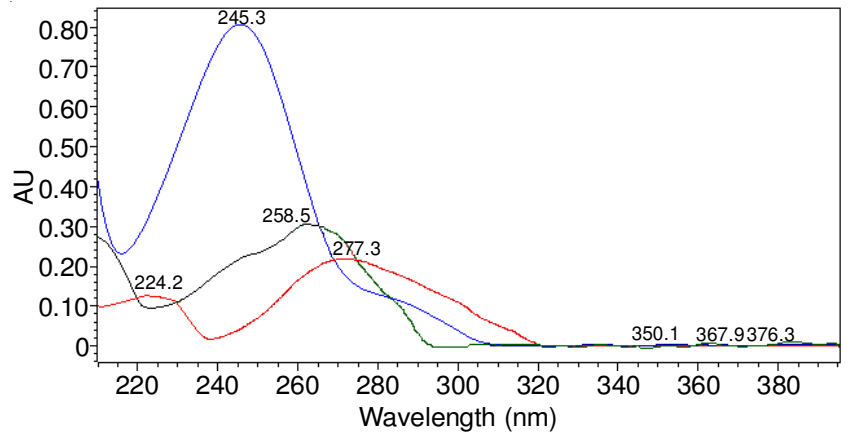

Fig. 4. Isobestic point of salbutamol, oxtriphylline and bromhexine hydrochloride

\section{Preparation of analytical solutions}

Preparation of $0.1 \%$ orthophosphoric acid buffer solution: $1 \mathrm{~mL}$ of orthophosphoric acid was pipetted into a 1000 $\mathrm{mL}$ volumetric flask and about $100 \mathrm{~mL}$ of milli-Q water was added and final volume was made up to $1000 \mathrm{~mL}$ with milli-
Q water, mixed in ultra sonicator and filtered through $0.45 \mu$ membrane filter.

Preparation of mobile phase: A mixture of above buffer 650 and $350 \mathrm{~mL}$ of acetonitrile was used as mobile phase. The solution was degassed in ultrasonic water bath for $5 \mathrm{~min}$, filtered through $0.45 \mu$ filter under vacuum filtration before using.

Diluent preparation: Acetonitrile and water mixed in the ratio of 50:50 v/v was used as diluents for sample and standard preparations.

Preparation of the standard solution: Accurately weighed and transferred $4 \mathrm{mg}$ of salbutamol and $16 \mathrm{mg}$ of bromhexine hydrochloride into a $100 \mathrm{~mL}$ volumetric flask (stock A), 200 $\mathrm{mg}$ of oxtriphylline into a $10 \mathrm{~mL}$ volumetric flask (stock B). Added about $3 / 4^{\text {th }}$ of diluent to both the flasks and sonicated for about $15 \mathrm{~min}$ to dissolve the drugs completely, then made up to the final volume with diluent. From each of the above solutions $1 \mathrm{~mL}$ from the above two stock solutions was pippetted out and transferred into a $10 \mathrm{~mL}$ volumetric flask and made up to the mark with diluent in order to get solutions of concentration 4, 200 and 16 ppm for salbutamol, oxtriphylline and bromhexine hydrochloride, respectively.

Preparation of sample solution: Weighed accurately 20 tablets, powdered and transferred an amount equivalent to 4 $\mathrm{mg}$ of salbutamol and $16 \mathrm{mg}$ of bromhexine hydrochloride and $200 \mathrm{mg}$ of oxtriphylline into a $100 \mathrm{~mL}$ volumetric flask. Added about $3 / 4^{\text {th }}$ of diluent and sonicated for about $25 \mathrm{~min}$ to dissolve the drugs completely, then made up to the final volume with diluent. From the above solution $1 \mathrm{~mL}$ was pippetted out and transferred into a $10 \mathrm{~mL}$ volumetric flask and made up to the mark with diluent in order to get solution of concentration 4, 200 and 16 ppm for salbutamol, oxtriphylline and bromhexine hydrochloride, respectively.

Method development and validation of HPLC: The suggested analytical method was validated according to ICH guidelines [22] with respect to certain parameters such as specificity, linearity, precision, accuracy, robustness and system suitability.

Linearity: The linearity of the method was established by injecting six different concentration levels of salbutamol (1 to $6 \mathrm{ppm}$ ), oxtriphylline (50 to $300 \mathrm{ppm}$ ) and bromhexine hydrochloride (4 to $24 \mathrm{ppm}$ ) solutions in to the HPLC system and peak areas were recorded (Figs. 5-7). The results were shown in Table-1.

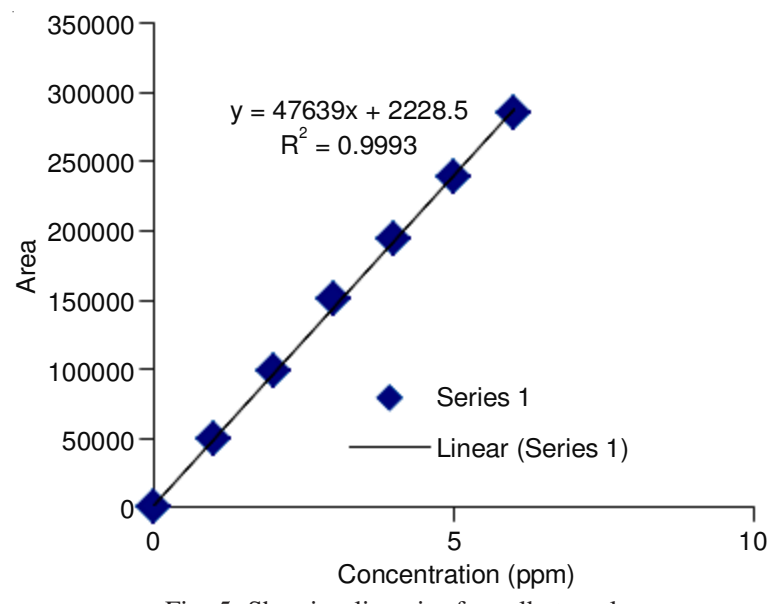

Fig. 5. Showing linearity for salbutamol 


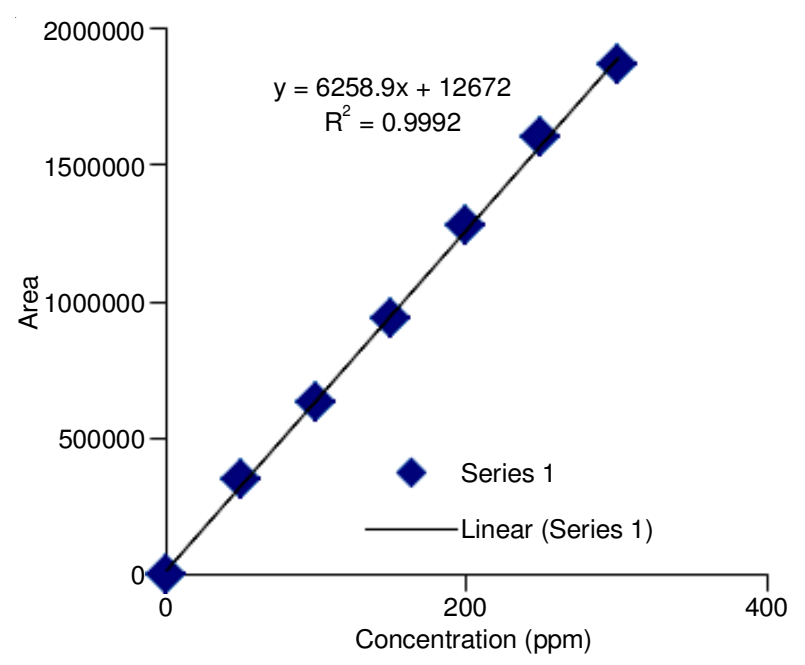

Fig. 6. Showing linearity for oxtriphylline

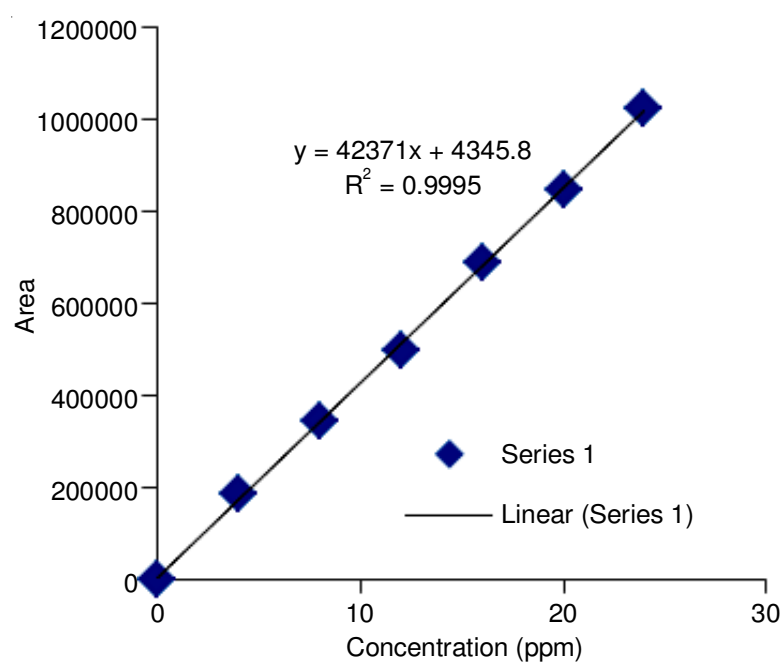

Fig. 7. Showing linearity for bromhexine $\mathrm{HCl}$

Specificity: The specificity was carried out to determine whether there are any interference of any impurities (presence of components may be unexpected to present) in retention time of analytical peak. Forced degradation studies are carried out by using $2 \mathrm{~N} \mathrm{HCl}, 2 \mathrm{~N} \mathrm{NaOH}$, heat and UV light. The graph obtained for injecting the standard solution of salbutamol, oxtriphylline and bromhexine hydrochloride was shown in the Fig. 8 .

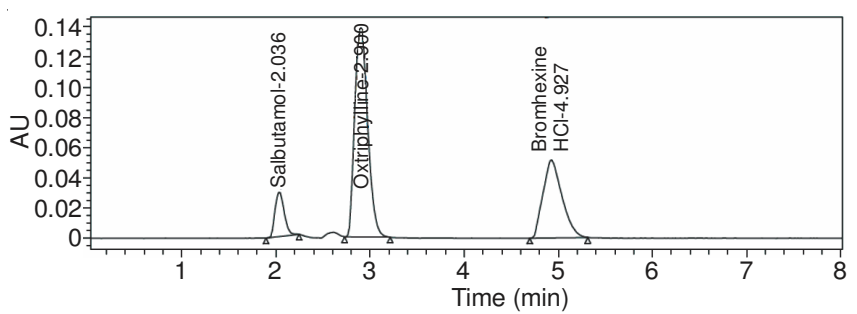

Fig. 8. Standard chromatogram of salbutamol, oxtriphylline and bromhexine hydrochloride

Precision: Precision expresses the closeness of agreement between the series of measurements obtained from multiple sampling of same homogeneous samples under the prescribed conditions. Method precision was determined both in terms of repeatability and intermediate precision/ruggedness (show the degree of reproducibility of test results obtained by analyzing the sample under variety of normal test conditions such as analyst to analyst variation and instrument to instrument variation). System precision was demonstrated by injecting six different standard solutions containing salbutamol equivalent to $4 \mathrm{ppm}$, oxtriphylline equivalent to $200 \mathrm{ppm}$ and bromhexine $\mathrm{HCl}$ equivalent to $16 \mathrm{ppm}$. The retention time, peak area values were expressed as mean and \%RSD calculated from the data obtained, which are found to be within the specified limits shown in Tables 3-5.

Accuracy: Accuracy was determined in terms of percentage recovery the accuracy study was performed for 50, 100 and $150 \%$ for salbutamol, oxtriphylline, bromhexine $\mathrm{HCl}$ standard and sample solutions are injected in to HPLC system in triplicate and percentage recoveries of salbutamol, oxtriphylline and bromhexine $\mathrm{HCl}$ were calculated. The area of each level was used for calculation of $\%$ recovery.

Robustness: Robustness of the method was demonstrated by deliberately changing the chromatographic conditions. The flow rate of the mobile phase changed from 1.0 to 0.9 and 1.1 $\mathrm{mL} / \mathrm{min}$. The temperature of the column was changed from 25 to 30 and $35{ }^{\circ} \mathrm{C}$. The solutions described for robustness study were applied on the column in triplicate and the responses were determined.

System suitability: System suitability tests were carried out on freshly prepared standard stock solutions of salbutamol, oxtriphylline and bromhexine $\mathrm{HCl}$ and it was calculated by injecting standards in six replicates and the values were recorded and are within the limits (\% RSD < 2) as shown in Table-7.

\section{RESULTS AND DISCUSSION}

The present investigation reported is a new RP-HPLC method development and validation of simultaneous estimation of salbutamol, oxtriphylline and bromhexine $\mathrm{HCl}$. The method developed was proceeding with wavelength selection. The optimized wavelength was $260 \mathrm{~nm}$. In order to get the optimized RP-HPLC method various mobile phases and columns were used. From several trials final method is optimized with the following conditions.

The mobile phase consists of an aqueous solution of $0.1 \%$ orthophosphoric acid and acetonitrile in the ratio of $65: 35 \%$ $\mathrm{v} / \mathrm{v}$ and the column used was kromasil C18 Column $(150 \mathrm{~mm}$ $\times 4.6 \mathrm{~mm}, 5 \mu \mathrm{m}$ particle size). The flow rate was adjusted to $1.0 \mathrm{~mL} / \mathrm{min}$. The instrument was operated at an ambient temperature. The UV detection was achieved at $260 \mathrm{~nm}$. The injection volume was $10 \mu \mathrm{L}$.

The specificity of the method was to determine whether there are any interference of any impurities (the presence of components may be unexpected to present) in retention time of analytical peak.

The linearity was determined as linearity regression of the claimed analyte concentration of the range 1 to $6 \mathrm{ppm}$ (Salbutamol) and 50 to $300 \mathrm{ppm}$ (oxtriphylline) 4 to $24 \mathrm{ppm}$ (bromhexine $\mathrm{HCl}$ ). The calibration curve obtained by plotting peak area versus concentration and presented in Table-1 was linear and the correlation coefficient was found to be 0.999 , 0.999 and 0.999 for salbutamol, oxtriphylline and bromhexine hydrochloride, respectively. 


\begin{tabular}{lccc}
\hline \multicolumn{3}{c}{ TABLE-1 } \\
LINEARITY RESULTS FOR SALBUTAMOL, OXTRIPHYLLINE \\
AND BROMHEXINE HYDROCHLORIDE \\
\hline Parameter & \multicolumn{3}{c}{ Regression equation parameters } \\
\cline { 2 - 4 } & Salbutamol & Oxtriphylline & Bromhexine \\
& & HCl \\
\hline Linearity range (ppm) & $1-6$ & $50-300$ & $4-24$ \\
Correlation co-efficient & 0.999 & 0.999 & 0.999 \\
Slope & 47639 & 6258 & 42371 \\
Y-intercept & 2228 & 12672 & 4345 \\
LOD (ppm) & 0.01 & 0.80 & 0.025 \\
LOQ (ppm) & 0.04 & 2.41 & 0.074 \\
\hline
\end{tabular}

The accuracy study was performed in 50, 100 and $150 \%$. The percentage recovery was determined for salbutamol, oxtriphylline and bromhexine hydrochloride and presented in Table-2.

Precision of the method was ascertained from determinations of peak areas of six replicates of sample solution. The $\%$ relative standard deviation for system precision presented in Tables 3-5 was found to be $0.7,0.2$ and 0.3 and the $\%$ relative standard deviation for method precision was found to be 1.0 , 0.5 and 0.7 .

\begin{tabular}{|c|c|c|c|}
\hline \multicolumn{4}{|c|}{$\begin{array}{c}\text { TABLE-2 } \\
\text { ACCURACY RESULTS }\end{array}$} \\
\hline Drugs & \multicolumn{2}{|c|}{ Spiked concentration (ppm) } & Recovery (\%) \\
\hline \multirow{3}{*}{ Salbutamol } & 2 & $50 \%$ & 99.46 \\
\hline & 4 & $100 \%$ & 99.33 \\
\hline & 6 & $150 \%$ & 98.46 \\
\hline \multirow{3}{*}{ Oxtriphylline } & 100 & $50 \%$ & 99.51 \\
\hline & 200 & $100 \%$ & 99.44 \\
\hline & 300 & $150 \%$ & 100.47 \\
\hline \multirow{3}{*}{$\begin{array}{c}\text { Bromhexine } \\
\mathrm{HCl}\end{array}$} & 8 & $50 \%$ & 100.08 \\
\hline & 16 & $100 \%$ & 99.36 \\
\hline & 24 & $150 \%$ & 98.46 \\
\hline
\end{tabular}

The robustness were carried out with minor but deliberate changes in parameters i.e., mobile phase, column temperature and flow rate as presented in Table-6. Theoretical plates and tailing factor were observed and were found to be 2177, 2175 and 2194 (theoretical plates) and 1.1, 1.2 and 1.3 (tailing factor) for salbutamol, oxtriphylline and bromhexine hydrochloride, respectively. The system suitability parameters like theoretical plates $(\mathrm{N})$ and tailing factor $(\mathrm{T})$ were calculated and were found to be more than 2000 and not more than 2 and ascertained that proposed RP-HPLC method was accurate and precise as

TABLE-3

SYSTEM PRECISION VALUES FOR SALBUTAMOL

\begin{tabular}{ccccc}
\hline S. No. & Peak name & Rt (min) & Area & USP plate count \\
\hline 1 & SAL_Injection-1 & 2.035 & 199939 & 2118 \\
2 & SAL_Injection-2 & 2.035 & 200590 & 2005 \\
3 & SAL_Injection-3 & 2.036 & 198897 & 2223 \\
4 & SAL_Injection-4 & 2.036 & 200069 & 1.15 \\
5 & SAL_Injection-5 & 2.036 & 197439 & 1.14 \\
6 & SAL_Injection-6 & 2.037 & 197750 & 1.17 \\
Mean & & & 199114 & 2034 \\
Std. Dev. & & & 1302.9 & 1.11 \\
RSD $(\%)$ & & & 0.7 & \\
\hline
\end{tabular}

TABLE-4

SYSTEM PRECISION VALUES FOR OXTRIPHYLLINE

\begin{tabular}{cccccc}
\hline S. No. & Peak name & Rt $(\mathrm{min})$ & Area & USP plate count & USP tailing \\
\hline 1 & OXT_Injection-1 & 2.900 & 1325424 & 2063 & 2145 \\
2 & OXT_Injection-2 & 2.901 & 1332302 & 2040 & 2206 \\
3 & OXT_Injection-3 & 2.901 & 1329213 & 2210 & 1.26 \\
4 & OXT_Injection-4 & 2.902 & 1328019 & 1.25 & 1.23 \\
5 & OXT_Injection-5 & 2.902 & 1329939 & 1.23 & 1.19 \\
6 & OXT_Injection-6 & 2.903 & 1331460 & & \\
Mean & & & 1329393 & \\
Std. Dev. & & & 2478.2 & & \\
RSD $(\%)$ & & & 0.2 & & \\
\hline
\end{tabular}

TABLE-5

SYSTEM PRECISION VALUES FOR BROMHEXINE HCl

\begin{tabular}{ccccc}
\hline S. No. & Peak name & Rt (min) & Area & USP plate count \\
\hline 1 & BRM_Injection-1 & 4.927 & 728959 & 2087 \\
2 & BRM_Injection-2 & 4.927 & 729406 & 2492 \\
3 & BRM_Injection-3 & 4.937 & 729913 & 2338 \\
4 & BRM_Injection-4 & 4.938 & 729210 & 1.29 \\
5 & BRM_Injection-5 & 4.940 & 733490 & 1.31 \\
6 & BRM_Injection-6 & 4.941 & 734475 & 1.29 \\
Mean & & & 730909 & 219 \\
Std. Dev. & & & 2421.5 & 1.32 \\
RSD $(\%)$ & & & 0.3 & \\
\hline
\end{tabular}




\begin{tabular}{lccc|ccc}
\hline & \multicolumn{3}{c}{ TABLE-6 } \\
& \multicolumn{3}{c}{ RESULTS OF ROBUSTNESS STUDY } \\
\hline \multirow{2}{*}{ Chromatographic conditions } & \multicolumn{3}{c}{ Average area } & & \multicolumn{3}{c}{ Rt (min) } \\
\cline { 2 - 7 } & Salbutamol & Oxtriphylline & $\begin{array}{c}\text { Bromhexine } \\
\text { hydrochloride }\end{array}$ & Salbutamol & Oxtriphylline & $\begin{array}{c}\text { Bromhexine } \\
\text { hydrochloride }\end{array}$ \\
\hline Buffer:Acetonitrile 60:40 (v/v) & 182547 & 1244813 & 679921 & 2.075 & 2.968 & 5.962 \\
Buffer:Acetonitrile 65:35 (v/v) & 199114 & 1329393 & 730909 & 2.036 & 2.901 & 4.937 \\
Buffer:Acetonitrile 70:30 (v/v) & 186221 & 1224724 & 677025 & 2.008 & 2.830 & 4.217 \\
Flow rate $(0.8 \mathrm{~mL} / \mathrm{min})$ & 224455 & 1518913 & 831857 & 2.249 & 3.210 & 5.441 \\
Flow rate $(1.0 \mathrm{~mL} / \mathrm{min})$ & 199114 & 1329393 & 730909 & 2.036 & 2.901 & 4.937 \\
Flow rate $(1.2 \mathrm{~mL} / \mathrm{min})$ & 184965 & 1254059 & 688434 & 1.858 & 2.643 & 4.523 \\
Temperature $\left(20^{\circ} \mathrm{C}\right)$ & 184053 & 1234710 & 677945 & 2.039 & 2.897 & 4.934 \\
Temperature $\left(25^{\circ} \mathrm{C}\right)$ & 199114 & 1329393 & 730909 & 2.036 & 2.901 & 4.937 \\
Temperature $\left(30^{\circ} \mathrm{C}\right)$ & 185747 & 1252496 & 690539 & 2.040 & 2.900 & 4.947 \\
\hline
\end{tabular}

\begin{tabular}{lcccc}
\multicolumn{5}{c}{ TABLE-7 } \\
\multicolumn{1}{c}{ SYSTEM SUITABILITY PARAMETERS } \\
\cline { 2 - 4 } \multicolumn{1}{c}{ Parameter } & Salbutamol & Oxtriphylline & Bromhexine hydrochloride & \multirow{2}{*}{ Limits } \\
\cline { 2 - 5 } & 1.41 & 0.53 & 1.12 & $<2.0$ \\
RSD of peak area & 0.04 & 0.04 & 0.13 & $<1.0$ \\
RSD of retention time & 1.1 & 1.2 & 1.3 & T \\
USP tailing factor (T) & 2177 & 2175 & 2194 & $>2000$ \\
USP plate count (N) & - & 4.3 & 6.5 & $>2$ \\
USP resolution (R) & & & & \\
\hline
\end{tabular}

\begin{tabular}{lcccccc}
\multicolumn{7}{c}{ TABLE-8 } \\
\cline { 2 - 6 } Stress conditions & \multicolumn{7}{c}{ Assay of active ingredients (\%) } \\
\cline { 2 - 7 } & Salbutamol & Degradation (\%) & Oxtriphylline & Degradation (\%) & $\begin{array}{c}\text { Bromhexine } \\
\text { hydrochloride }\end{array}$ & Degradation (\%) \\
\hline Acid, $2 \mathrm{~N} \mathrm{HCl}$ & 95.86 & 4.14 & 95.64 & 4.36 & 95.83 & 4.17 \\
$\mathrm{Base}, 2 \mathrm{~N} \mathrm{NaOH}$ & 97.10 & 2.90 & 96.77 & 3.23 & 96.91 & 3.09 \\
$\mathrm{H}_{2} \mathrm{O}_{2}(20 \%, \mathrm{v} / \mathrm{v})$ & 98.22 & 1.78 & 98.27 & 1.73 & 97.99 & 2.01 \\
Dry heat $\left(80^{\circ} \mathrm{C}\right)$ & 98.90 & 1.10 & 98.31 & 1.69 & 99.05 & 0.95 \\
UV & 99.45 & 0.55 & 99.34 & 0.66 & 99.21 & 0.79 \\
Water & 99.55 & 0.45 & 99.47 & 0.53 & 99.36 & 0.64 \\
\hline
\end{tabular}

presented in Table-7. Forced degradation studies were performed to establish the stability indicating property and specificity of the proposed method. Degradation studies were carried out under conditions of acid hydrolysis, base hydrolysis, thermal, oxidation and photolysis and the drug substances were observed high degradation in acid $(2 \mathrm{~N} \mathrm{HCl})$ comparative remaining in all conditions. Thermal degradation conditions were performed by heating the drug sample at $80^{\circ} \mathrm{C}$. Acid and base hydrolysis showed 3-4\% degradation, very slight degradation observed in oxidation, thermal, photolytic hydrolysis. The results of forced degradation studies were given in Table-8.

\section{Conclusion}

A new stability indicating method was established for simultaneous estimation of salbutamol, oxtriphylline and bromhexine hydrochloride by RP-HPLC method. The analytical method was validated according to ICH guidelines ( ICH, Q2 (R1).All the validation parameters were found within limits as per ICH guidelines. Hence the suggested RP-HPLC method can be used for routine analysis of salbutamol, oxtriphylline and bromhexine hydrochloride in API and pharmaceutical tablet dosage form.

\section{ACKNOWLEDGEMENTS}

The authors are grateful to Spectrum Pharma Pvt. Ltd., Hyderabad, India for providing the gift samples of salbutamol, oxtriphylline and bromhexine hydrochloride. The authors are also grateful to Department of Technical Education, Government Polytechnic-Masabtank, Hyderabad, India for providing necessary facilities to carry out the research work.

\section{REFERENCES}

1. C.R. Reinero, C. Delgado, C. Spinka, A.E. Declue and R. Dhand, Int. Arch. Allergy Immunol., 150, 43 (2009); https://doi.org/10.1159/000210379.

2. United State Pharmacopeia, 28th ed., National Formulary, 23rd ed., 57; Pharmacopeial forum, Salbutamol sulfate, 27(3) 2506.

3. O. Agostini, A. Chiari and D.C. Baffoni, Boll. Chim. Farm., 121, 612 (1982).

4. S.V. Erram, C.B. Fanska and M. Asif, J. Pharm. Biomed. Anal., 40, 864 (2006); https://doi.org/10.1016/j.jpba.2005.08.021.

5. L. Malkki and S. Tammilehto, J. Pharm. Biomed. Anal., 11, 79 (1993); https://doi.org/10.1016/0731-7085(93)80151-P.

6. N. Beaulieu, T.D. Cyr and E.G. Lovering, J. Pharm. Biomed. Anal., 8, 583 (1990); https://doi.org/10.1016/0731-7085(90)80084-3. 
7. H. Ong, A. Adam, S. Perreault, S. Marleau, M. Bellemare, P. Du Souich and N. Beaulieu, J. Chromatogr. A, 497, 213 (1989); https://doi.org/10.1016/0378-4347(89)80020-9.

8. A. Halabi, C. Ferrayoli, M. Palacio, V. Dabbene and S. Palacios, J. Pharm. Biomed. Anal., 34, 45 (2004); https://doi.org/10.1016/i.japna.2003.08.020.

9. M. Senthilraja and P. Giriraj, Asian J. Pharm. Clin. Res., 4, 13 (2011).

10. V.L. Herring and J.A. Johnson, J. Chromatogr. B Biomed. Sci. Appl., 741, 307 (2000); https://doi.org/10.1016/S0378-4347(00)00107-9.

11. Y. Zhang and Z.R. Zhang, J. Chromatogr. B Analyt. Technol. Biomed. Life Sci., 805, 211 (2004);

https://doi.org/10.1016/j.jchromb.2004.02.037.

12. E.V. Rao, G.R. Rao, S. Raghuveer and P. Khadgapathi, Analyst, 112, 871 (1987); https://doi.org/10.1039/an9871200871.

13. A. El-Gindy, S. Emara and H. Shaaban, J. Pharm. Biomed. Anal., 43, 973 (2007);

https://doi.org/10.1016/j.jpba.2006.09.020.
14. P.N.S. Pai, G.K. Rao, M.S. Murthy, A. Agarwal and S. Puranik, Indian J. Pharm. Sci., 71, 53 (2009); https://doi.org/10.4103/0250-474X.51957.

15. B. Jayalakshmi, J. Ramesh, T.N. Kalpana and R. Vijayamirtharaj, J. Pharm. Res., 3, 2868 (2010).

16. A. Gupta, R. Garg and A.K. Sharma, Indian J. Pharm. Sci., 60, 407 (1998).

17. R. Kimbahune, K. Sunil, P. Kabra, K. Delvadiya and S. Surani, Int. J. Pharm. Sci. Rev. Res., 8, 24 (2011).

18. D. Jain, S. Jain, D.K. Jain and P. Trivedi, Indian J. Pharm. Sci., 60, 238 (1998).

19. S.K. Panda and A.K. Sharma, Indian J. Pharm. Sci., 61, 116 (1999).

20. V. Gupta, M. Verma, U. Misra and R.K. Nema Asian J. Chem., 21, 1633 (2009).

21. H.L. Rau, A.R. Aroor and P.G. Rao, Indian J. Pharm. Sci., 52, 255 (1990).

22. International Conference on Harmonization, Technical Requirements for Registration of Pharmaceuticals for Human Use, ICH Harmonized Tripartite Guideline Validation of Analytical Procedures: Text and Methodology Q2 (R1), Geneva, Switzerland (1996). 